\title{
$P$. acnes-Driven Disease Pathology: Current Knowledge and Future Directions
}

\author{
Joerg R. Leheste ${ }^{1 *}$, Kathryn E. Ruvolo ${ }^{1}$, Joanna E. Chrostowski ${ }^{1}$, Kristin Rivera ${ }^{1}$, \\ Christopher Husko ${ }^{1}$, Alyssa Miceli ${ }^{1}$, Martin K. Selig ${ }^{2}$, Holger Brüggemann ${ }^{3}$ and \\ German Torres ${ }^{1}$
}

${ }^{1}$ Department of Biomedical Sciences, NYIT College of Osteopathic Medicine, Old Westbury, NY, USA, ${ }^{2}$ Molecular Pathology Division, Massachusetts General Hospital and Harvard Medical School, Boston, MA, USA, ${ }^{3}$ Department of Biomedicine, Aarhus University, Aarhus, Denmark

This review discusses the biology and behavior of Propionibacterium acnes (P.acnes), a dominant bacterium species of the skin biogeography thought to be associated with transmission, recurrence and severity of disease. More specifically, we discuss the ability of $P$. acnes to invade and persist in epithelial cells and circulating macrophages to subsequently induce bouts of sarcoidosis, low-grade inflammation and metastatic cell growth in the prostate gland. Finally, we discuss the possibility of $P$. acnes infiltrating the brain parenchyma to indirectly contribute to pathogenic processes in neurodegenerative disorders such as those observed in Parkinson's disease (PD).

Keywords: Propionibacterium acnes, sarcoidosis, BPH, prostate cancer, Parkinson disease

\section{OPEN ACCESS}

Edited by:

Francois Vandenesch, University of Lyon, France

Reviewed by: John K. Crane University at Buffalo, USA Jan Potempa,

University of Louisville, USA

*Correspondence: Joerg R. Leheste jleheste@nyit.edu

Received: 19 November 2016 Accepted: 01 March 2017 Published: 14 March 2017

Citation:

Leheste JR, Ruvolo KE, Chrostowski JE, Rivera K, Husko C, Miceli A, Selig MK, Brüggemann H and Torres G (2017) P. acnes-Driven Disease Pathology: Current Knowledge and Future Directions. Front. Cell. Infect. Microbiol. 7:81. doi: 10.3389/fcimb.2017.00081

\section{GENERAL OVERVIEW}

A large fraction of microorganisms not only reside within us but also live on us. Indeed, the human skin harbors a heterogeneous mix of mostly non-pathogenic bacteria, fungi and viruses that probably contribute to skin surface health (Figure 1). Propionibacterium acnes (P. acnes) is a ubiquitous, slow growing, rod-shaped, non-spore forming, Gram-positive anaerobe (Figure 2) found across body sites, including sebaceous follicles of the face and neck (Funke et al., 1997; Grice and Segre, 2011; Findley and Grice, 2014). It is often considered part of our commensal microbiota at barrier sites (Cogen et al., 2008) which is established via mechanisms of adaptive immune tolerance during the early neonate period (Scharschmidt et al., 2015). Although the topographical distribution of the anaerobe in sebaceous sites is significant, the spatial and personal distribution of $P$. acnes is more individual-specific than site-specific (Oh et al., 2014). Moreover, the biogeography and individuality of $P$. acnes is highly dynamic as changes in health or changes in $\mathrm{pH}$, temperature, moisture and/or sebum content may also affect the range of niches occupied by the microorganism (Grice et al., 2009). Similar to the distribution of skin microbes, skin conditions can also shape the function of $P$. acnes in terms of pathogen expansion in disease. For example, $P$. acnes has been linked to skin insults such as acne vulgaris in the face and neck, and progressive macular hypermelanosis on the back (Bojar and Holland, 2004; Kurokawa et al., 2009; Barnard et al., 2016). In addition, certain disease-associated phylotypes of $P$. acnes have the ability to persist on body implants and surgical devices causing a wide-range of post-operative infectious conditions, such as endocarditis, endophthalmitis and intravascular nervous system infections (Perry and Lambert, 2011; Portillo et al., 2013). The untoward features of P. acnes also extend to the prostate gland where tissue invasion and intracellular deposition of the bacterium has been 


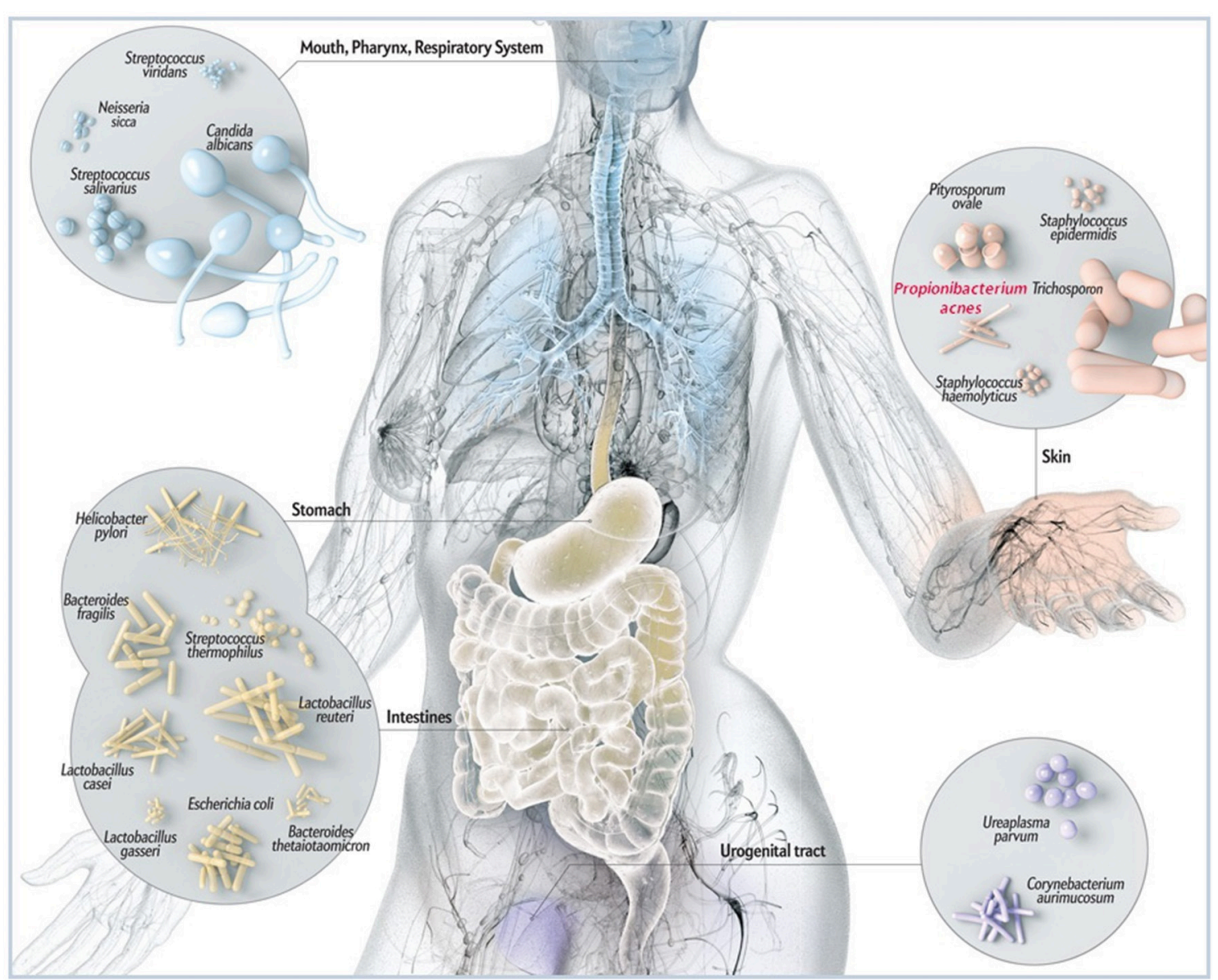

FIGURE 1 | Schematic illustration of common microbes found at barrier sites in humans including $\boldsymbol{P}$. acnes. While $P$. acnes is present on all external and internal surfaces (i.e., oral and gastrointestinal epithelia, conjunctiva), it is most prevalent on the human skin. There it resides in hair follicles of the face and back where it is associated with the common skin disease acne vulgaris. By most, $P$ acnes is still considered a mostly benign and commensal microorganism, however, reports about its malicious opportunistic side are increasing. Adapted and with kind permission from Bryan Christie Design (http://bryanchristiedesign.com/).

frequently noted in glandular epithelial cells and circulating macrophages; a phenomenon thought to indirectly contribute to benign prostate hyperplasia (BPH) and prostate cancer (Tanabe et al., 2006; Alexeyev et al., 2007; Fassi-Fehri et al., 2011; Mak et al., 2012; Bae et al., 2014; Davidsson et al., 2016). However, it is not clear what the underlying mechanisms used by $P$. acnes are to induce infection, inflammation and/or metastasis outside the skin. What is known with some certainty is that bacteria-infected keratinocytes, sebocytes and/or adipocytes secrete several proinflammatory chemokines and cytokines as well as anti-microbial factors (e.g., cathelicidin) hinting at specific disease mechanisms (Graham et al., 2004; Nagy et al., 2006; Lee et al., 2010; Zhou et al., 2015; Sanford et al., 2016; Yu et al., 2016).

\section{SARCOIDOSIS}

Sarcoidosis is a disease of unknown etiology that leads to inflammation in organs as diverse as lungs, liver, skin and lymphatics. A putative link of sarcoidosis with $P$. acnes was first proposed when the bacterium was isolated from sarcoid lesions of the skin and lymph nodes (Eishi et al., 2002; Yamada et al., 2002). These findings have been significantly corroborated (de Brouwer et al., 2015), and further expanded by various in vitro experiments demonstrating the invasion capacity of $P$. acnes in HEK293T (human embryonic kidney) and A549 (human alveolar epithelial carcinoma) cell lines (Tanabe et al., 2006). Most recent work in sarcoid broncho-alveolar lavage (BAL) fluid and cells showed significant upregulation of a $P$. acnes-specific immune response (Schupp et al., 2015). In addition, experiments in mice have shown that viable $P$. acnes can induce pulmonary granulomas similar to those observed in sarcoidosis patients (Werner et al., 2017). A general overview detailing the link between sarcoidosis and $P$. acnes is further given by Eishi (2013).

Studies attempting to characterize the signaling pathways activated by $P$. acnes during infection showed that nuclear factor-kappaB $[\mathrm{NF}-\kappa \mathrm{B}]$, a transcriptional factor that regulates the expression of genes involved in immune and inflammatory cascades is activated by P. acnes (Kim et al., 2002). More broadly, toll-like receptor 2 (TLR2) was shown to be a critical receptor for the NF-кB-dependent response to $P$. acnes, revealing the capacity 

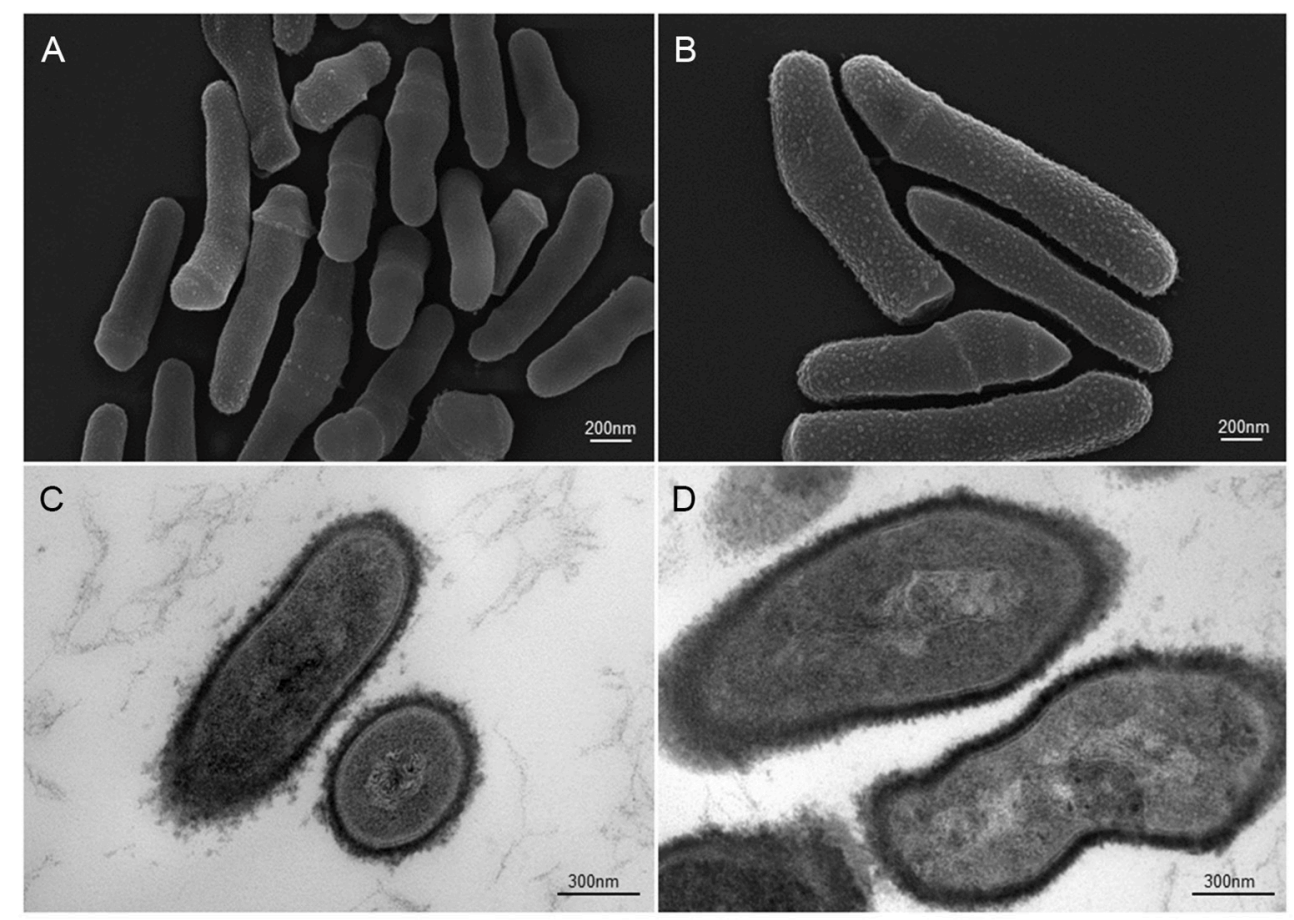

FIGURE 2 | Scanning and transmission electron microscopic (SEM and TEM) images of $\boldsymbol{P}$ acnes strain KPA (A, B = SEM; C, D = TEM). Recent advances in isolation and culturing techniques are revealing that $P$. acnes infections have been grossly underestimated shedding a new light on this opportunistic bacterial species. Microscopy by Volker Brinkmann, Max Planck Institute for Infection Biology, Berlin, Germany. Scale bar = 200/300nm.

of this bacterium to provoke the selective activation of innate immunity genes (Inohara and Nuñez, 2001; Chamaillard et al., 2003; Moreira and Zamboni, 2012). Furthermore, the role of host genetics was examined in sarcoidosis cases that were associated with $P$. acnes infection. Single nucleotide polymorphisms (SNPs) in the nucleotide-binding oligomerization domain (NOD) of proteins NOD1 and NOD2 were correlated with $P$. acnes infection among 73 sarcoidosis patients with 52 interstitial pneumonia and 215 healthy controls (Tanabe et al., 2006). NOD1 and NOD2 are intracellular pattern recognition receptors that can sense bacterial molecules such as peptidoglycan moieties. Along the same lines, in vitro experiments have shown that internalization of $P$. acnes into HEK293T cells can result in activation of NOD1 and NOD2, suggesting a disease mechanism based on chronic inflammation or local immunosuppression (Tanabe et al., 2006). These findings also suggest that invasive $P$. acnes can act as bacterial ligands to cause aberrant NOD receptor activation in certain individuals with long-lasting susceptibility to sarcoidosis. However, future experiments have to clarify the exact mechanistic chronology of whether or how $P$. acnes-mediated aberrant NF- $\kappa \mathrm{B}$ activation may induce granuloma formation in a NOD1/NOD2-dependent manner.

Although invasive $P$. acnes could be a possible etiology of sarcoidosis and perhaps other diseases, elucidating causation and correlation between $P$. acnes infection and pathology is murky as bacterial strain heterogeneity, host genetics as well as host's environments must be considered whenever a study links a microbiome to a disease state.

\section{BENIGN PROSTATE HYPERPLASIA (BPH) AND PROSTATE CANCER}

Chronic or recurrent inflammatory processes have long been implicated in the progression of $\mathrm{BPH}$ and prostate cancer (De Marzo et al., 1999; Nelson et al., 2004; Sfanos et al., 2014). Inflammation is attributed to the presence of specific biomarkers such as elevated interleukin (IL)-6, tumor necrosis factor alpha $(\mathrm{TNF} \alpha)$ and the acute phase protein, $\mathrm{C}$ reactive protein (Mechergui et al., 2009; Menschikowski et al., 2013; Yu et al., 2015). Recent work on urological fluids (i.e., urine, seminal fluid, prostatic secretions) as well as prostate biopsies suggests a significant conditional shift toward certain microbial species which may be used as a diagnostic index (Yu et al., 2015; Ni et al., 2016).

A good amount of work is suggesting that the specific association of $P$. acnes with the prostate and the invasion of prostate epithelial cells in particular (Figure 3) may contribute to the pathology of $\mathrm{BPH}$ or prostate cancer with an inflammatory component (Sfanos et al., 2013; Davidsson et al., 2016). However, it is currently unclear whether $P$. acnes represents a true infectious agent of the prostate, a commensal or accidental prostate microbion. It is plausible that prostate-located P. acnes 


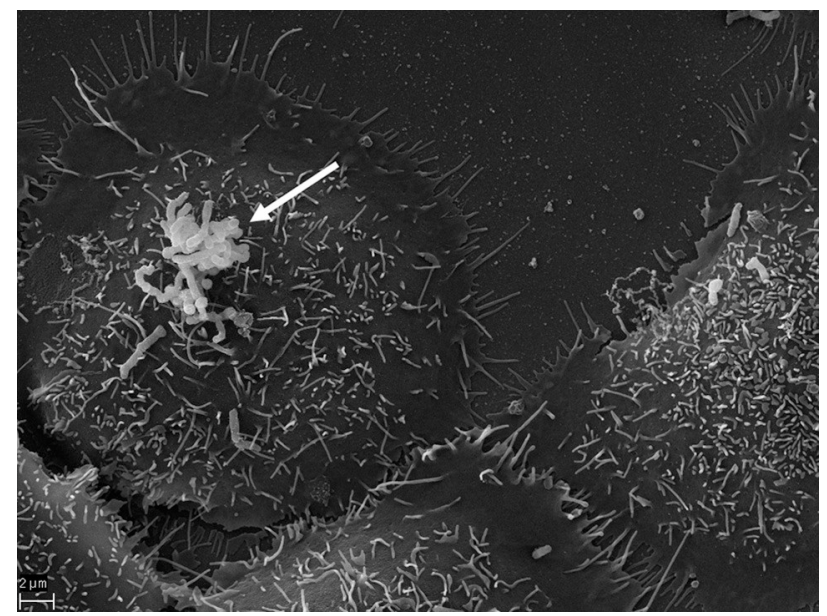

FIGURE 3 | SEM of $P$. acnes strain P6 (arrow) in vitro on cultured prostate epithelial cells RWPE1. The prostate epithelial cell-invasive behavior of $P$. acnes is well documented in both, in vivo and cell-based studies where a vimentin-mediated invasion process looks likely (Mak et al., 2012). Microscopy by Volker Brinkmann, Max Planck Institute for Infection Biology, Berlin, Germany. Scale bar $=2 \mu \mathrm{m}$.

are derived from the skin that are accidentally introduced, for instance during a prostate biopsy-a viewpoint that should raise concerns with certain diagnostic workup scenarios.

Whatever the route of entry or pathogenic potential, a significant number of prostate tissues obtained through transurethral resection for $\mathrm{BPH}$, or radical prostatectomy for cancer, were previously tested positive for $P$. acnes aggregates apparently residing within roving macrophages (Alexeyev et al., 2007; Bae et al., 2014). Additional reports based on human samples have provided further evidence for a link between $\mathrm{BPH}$ or prostate cancer and $P$. acnes using various technical approaches, including cultivation, confocal microscopy for visualization of the bacterium and in situ hybridization, immunohistochemistry (Figure 4) and PCR-based profiling of bacterial 16S rRNA (Hochreiter et al., 2000; Cohen et al., 2005; Sfanos et al., 2008; Fassi-Fehri et al., 2011; Bae et al., 2014; Davidsson et al., 2016). Further evidence comes from animal studies indicating that inoculation of $P$. acnes into the murine or rat prostate and bladder leads to an overt, long-term inflammatory response and a wide-range of cellular disturbances within the prostate gland (Olsson et al., 2012; Shinohara et al., 2013).

Attempts to phylogenetically analyze disease-associated $P$. acnes strains from cancerous prostate glands have revealed that most prostate isolates belong to phylogenetic clades that are rare on human skin, indicating that a skin-derived contamination during sampling is unlikely (Mak et al., 2013; Davidsson et al., 2016). Along the same lines, similar inflammatory pathways as those described for sarcoidosis, including NF-кB, IL-6, STAT3 and COX2, appear to be activated by $P$. acnes both under in situ and in vitro conditions (Drott et al., 2010; Fassi-Fehri et al., 2011; Mak et al., 2013; Tsai et al., 2013; Bae et al., 2014). Although the precise etiology for these inflammatory changes
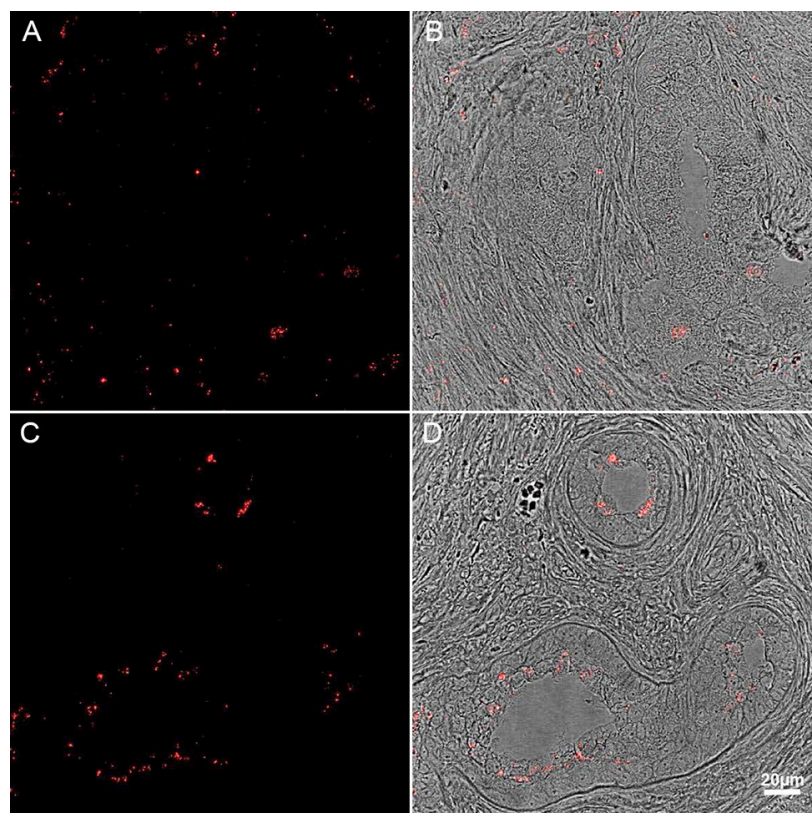

FIGURE 4 | Immunohistochemistry of human prostate tissue samples stained with $\boldsymbol{P}$. acnes antibody (red). Adapted with permission from Fassi-Fehri et al., 2011 (Supplementary Figure 2B). Presence of $P$. acnes in human prostate tissue samples with benign prostatic hyperplasia $\mathbf{( A , B ) ; ~ o r ~}$ adenocarcinoma (C,D). Extensive bacterial load was detected in both cases.

is not yet clear, several membrane-bound pattern recognition receptor pathways are broadly distributed in mammalian urinary and genital systems that avidly recognize bacterial and viral components (Jorgensen and Seed, 2012; Gambara et al., 2013). These host cell receptors, for example TLRs, promote cytokine production which is a core feature of innate immunity against microbial pathogens. Collectively, these findings suggest that through their capacity to trigger various aspects of immunity, invading $P$. acnes can act as primary driver and/or amplifier of disease severity.

\section{SPONDYLODISCITIS AND BACK PAIN}

One of several post-operative complications involving $P$. acnes is inflammation of the intervertebral disk and the surrounding intervertebral space (diskitis) following discectomy (Harris et al., 2005). Concomitant degenerative infection of adjacent vertebrae (spondylodiscitis) can be a common feature and the root cause for serious neurological damage and pain if treatment is delayed (Uçkay et al., 2010). Aside from unintentional surgical introduction right into the vertebral column, pathogens can also arrive through the arterial and venous spinal blood supply (hematogenous spreading). While Staphylococcus aureus, Escherichia coli, and Proteus species are most commonly isolated, $P$. acnes is the most abundant anaerobic pathogen in this context and likely underreported due to culturing challenges. There has been some clinical evidence that patients with herniated nuclear (nucleus pulposus) disk material infected with 
anaerobic pathogens in general, and $P$. acnes in particular, are more likely develop inflammation and edema of the adjacent vertebrae (Modic changes type I) and back pain (Albert et al., 2013; Urquhart et al., 2015). Clinical and animal-based followups are now corroborating the initial findings showing that local $P$. acnes proliferation causes upregulation of inflammatory markers and disk degeneration consistent with Modic changes (Aghazadeh et al., 2016; Dudli et al., 2016). There is now even first clinical evidence to suggest that bacterial infection of the intervertebral disk with P. acnes and/or Staphylococcus epidermidis may actually precede all other issues as the root cause of disk herniation and associated pathological changes (Rajasekaran et al., 2017).

\section{PARKINSON'S DISEASE (PD)}

The degenerating brain is characterized by neural system damage that may be attributed to atypical aggregation and deposition of mutant or misfolded proteins (e.g., Lewy bodies and Lewy neurites) as clearly documented in idiopathic PD (Taylor et al., 2002). What is generally not appreciated is that the brain is also susceptible to invading pathogens ranging from viruses and bacteria to fungi. These pathogens, or more specifically their endogenous components and/or metabolites, can produce central neurological deficits ranging from subtle signs of dementia and dystonia, which result from chronic, recurrent infection (De Chiara et al., 2012; Bibi et al., 2014), to more severe motor neuron disease as for example observed with the human endogenous retrovirus K (Li et al., 2015). Thus, it is clear that humans have a tremendously heavy systemic burden of microbes (Potgieter et al., 2015; Spadoni et al., 2015) which may incidentally contribute to the pathology of progressive neurodegenerative diseases with atypical protein component. Certainly, this working hypothesis is gaining considerable support as cognitive, emotional or pathological behavior appear to be indirectly affected by the spatial and personal distribution of microbes acting through the gutbrain axis (Figure 5) (Collins et al., 2012; Dinan et al., 2013; Mayer et al., 2014; Burokas et al., 2015). Indeed, a recent case-control study demonstrated that microbial variation in the gastrointestinal tract, both between and within individuals; correspond most significantly to phenotypical variations in PD (Scheperjans et al., 2015; Vizcarra et al., 2015). Although the underlying mechanisms linking microbiota composition with differences in $\mathrm{PD}$ are not clear, the above finding might at least explain the high prevalence of gastrointestinal abnormalities seen in PD patients (Dobbs et al., 2016). Further linking the microbiota to PD severity, sigmoid mucosal biopsies and fecal material collected from PD patients showed the presence of opportunistic and pro-inflammatory bacterial species that often cause chronic constipation, irritable bowel syndrome and ulcerative colitis (Keshavarzian et al., 2015). Collectively, these initial results suggest that relationships between different microbial communities in the gut are a common comorbidity in $\mathrm{PD}$, and that unique individual signatures of the gut ecosystem can reinforce classic motor impairments of $\mathrm{PD}$.
Against this background, the question to be asked is whether there is any evidence that $P$. acnes plays any role in the pathophysiology of $\mathrm{PD}$. For this possibility to occur, two conditions must be met: (1) P. acnes infection must precede the occurrence of classic symptoms of the disease such as shaking, motor initiation and slowness of movement; and (2) P. acnes inoculation must sufficiently induce symptoms of PD and/or lead to the loss of dopamine projection neurons in the midbrain nucleus known as substantia nigra pars compacta. So far, our laboratory has detected clusters of $P$. acnes localized to neurons of the midbrain and nearby cortical structures of autopsied PD brains (Figure 6). This unexpected finding adds further credence of $P$. acnes indirectly contributing to local bouts of inflammation similar to those seen in sarcoidosis and BPH. An open question is the extent to which $P$. acnes can indirectly enhance certain pathological features of PD. As PD is a highly heterogeneous disorder, it is unlikely that one disease mechanism applies to all PD phenotypes. Nevertheless, it is intriguing to speculate that resident skin microbes could initiate or amplify PD progression through inflammatory and/or genetic predisposition factors.

If $P$. acnes can gain access to dopamine cells in the midbrain, what is the most likely route of inoculation and infection? Although the skin is physically compartmentalized from the brain, cross-inoculation remains a risk factor. For example, the nares could potentially harbor pathogenic $P$. acnes strains which would then translocate to the brain parenchyma to hyper-activate local macrophages called microglia; a phenomenon that is a

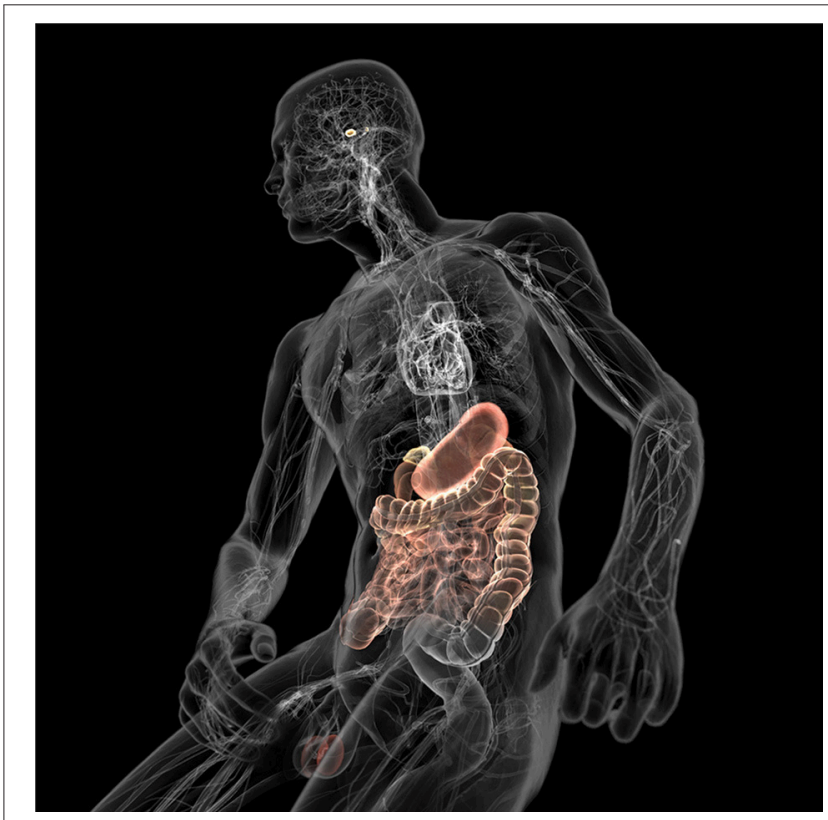

FIGURE 5 | Schematic illustration of the gut-brain axis (colored) with the microbe-filled digestive system on one end and the brain with its homeostasis centers (hypothalamus and pituitary) on the other. Both are connected through the cardiovascular and autonomic nervous system including the vagus nerve (cranial nerve $X$ ) which could facilitate microbial transition into the central nervous system (CNS). Kindly with permission from Bryan Christie Design (http://bryanchristiedesign.com/). 


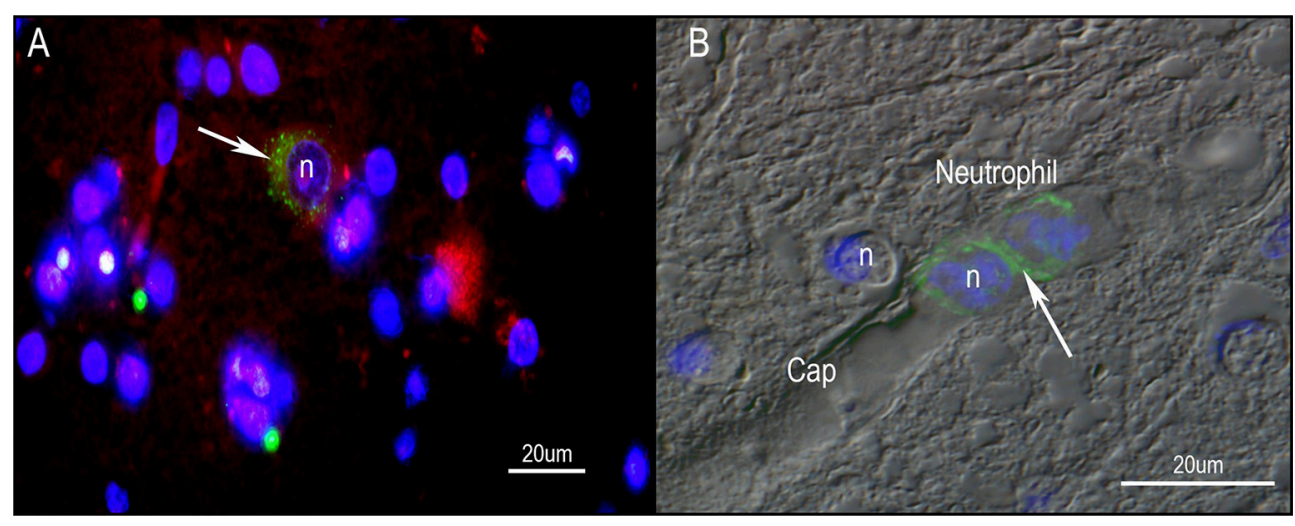

FIGURE 6 | Immunohistochemistry of human PD midbrain tissue samples stained for $\boldsymbol{P}$. acnes (green; A+B), neuronal microtubules (MAP2; red; A) and nuclei (DAPI; blue; A+B). Age-linked lipofuscin auto-fluorescence was extinguished with Sudan Black B. Presence of $P$. acnes (arrow) in the periplasmic space of a human neuron (A) between nucleus (n) and cytoskeleton; or neutrophil (B) with its characteristic multi-lobed nucleus inside a midbrain capillary (Cap). These findings are typical for PD and absent in most control sections. Retrograde movements along cranial nerves, trauma-induced micro-bleeds as well as the newly discovered glymphatic system represent potential microbial pathways into the CNS.

consistent feature of PD pathology (reviewed by Chao et al., 2014). Research into nosocomial infections demonstrate bacterial species as diverse as Pneumococcus sp. (Zwijnenburg et al., 2001) and Salmonella sp. (Bollen et al., 2008) roving readily along the olfactory nerve (cranial nerve 1; CN 1) and eventually into the olfactory bulb. Another potential route of entrance for harmful microbes or dangerous misfolded proteins is the vagus nerve (cranial nerve 10; $\mathrm{CN} 10$ ). Indeed under some circumstances, misfolded aggregates in the form of Lewy bodies and Lewy neurites appear to migrate from the vagus nerve to the brain, providing further evidence for pathogenic bacteria in association with toxic proteins to potentially contribute to selective neuronal vulnerability (Holmqvist et al., 2014). Of interest, brain nuclei of $\mathrm{CN} 1$ and $\mathrm{CN} 10$ are among the first sites to preferentially show deposition of Lewy bodies and Lewy neurites during the course of PD progression (Braak et al., 2004). This particular observation not only highlights a likely route of entrance for bacteria into the brain, but also provides a potential mechanism for the observation that truncal vagotomy significantly decreases the PD risk (Svensson et al., 2015). The link between head trauma and PD (Harris et al., 2013; Jafari et al., 2013; Pearce et al., 2015), together with the notion of a diverse blood microbiome (Potgieter et al., 2015), implies a vast potential for pathogenic opportunism as traumatic breaches in the blood brain barrier occur. With the recent discovery of a brain lymphatic (glymphatic) system (Iliff et al., 2012; Hitscherich et al., 2016) another potential route of brain infection must be considered.

Taken together, there is preclinical and some clinical evidence to indirectly implicate $P$. acnes as an independent variable affecting PD incidence or severity. This evidence is complemented by reports associating a severe skin disorder, acne inversa, with Alzheimer's disease (Wang et al., 2010). From a therapeutic perspective, the possibility of $P$. acnes driving or amplifying core features of PD represents an important resource for antibiotic approaches to neurodegenerative diseases. And from a research perspective, it would be worthy to examine patients with skin disorders more closely for evidence of neuropathology with earlier onset and a more severe disease phenotype.

\section{FUTURE OUTLOOK}

The review presented in this article outlines an unexpected dark side of $P$. acnes with respect to pathology. Intracellular persistence of $P$. acnes is implicated in diseases of the lungs and prostate gland and possibly the brain. This is a clear testimony for the pathogenicity of skin-derived bacteria in certain disease phenotypes. Further investigation will need to focus on several looming questions in $P$. acnes biology: (1) what are the crucial $P$. acnes interactions in disease susceptibility? (2) What are the mechanisms used by $P$. acnes to influence disease progression? (3) If certain populations of $P$. acnes can enhance susceptibility to disease severity, are there other configurations of $P$. acnes that are protective? (4) Proof of concept that P. acnes infection directly associates with disease pathology, or more specifically, does the study of concept show causation or just correlation? And finally (5) Can P. acnes-driven disease pathology be treated with conventional antibiotic therapy and diagnostic applications?

\section{AUTHOR CONTRIBUTIONS}

JL, KER, JC, KR, CH, AM, HB, and GT prepared the manuscript. $\mathrm{JL}$ and MS prepared the figures.

\section{FUNDING}

Intramural funding to JL was provided by NYIT College of Osteopathic Medicine. 


\section{REFERENCES}

Aghazadeh, J., Salehpour, F., Ziaeii, E., Javanshir, N., Samadi, A., Sadeghi, J., et al. (2016). Modic changes in the adjacent vertebrae due to disc material infection with Propionibacterium acnes in patients with lumbar disc herniation. Eur. Spine J. doi: 10.1007/s00586-016-4887-4. [Epub ahead of print].

Albert, H. B., Lambert, P., Rollason, J., Sorensen, J. S., Worthington, T., Pedersen, M. B., et al. (2013). Does nuclear tissue infected with bacteria following disc herniations lead to Modic changes in the adjacent vertebrae? Eur. Spine J. 22, 690-696. doi: 10.1007/s00586-013-2674-z

Alexeyev, O. A., Marklund, I., Shannon, B., Golovleva, I., Olsson, J., Andersson, C., et al. (2007). Direct visualization of Propionibacterium acnes in prostate tissue by multicolor fluorescent in situ hybridization assay. J. Clin. Microbiol. 45, 3721-3728. doi: 10.1128/JCM.01543-07

Bae, Y., Ito, T., Iida, T., Uchida, K., Sekine, M., Nakajima, Y., et al. (2014). Intracellular Propionibacterium acnes infection in glandular epithelium and stromal macrophages of the prostate with or without cancer. PLOS ONE 9:e90324. doi: 10.1371/journal.pone.0090324

Barnard, E., Liu, J., Yankova, E., Cavalcanti, S. M., Magalhães, M., Li, H., et al. (2016). Strains of the Propionibacterium acnes type III lineage are associated with the skin condition progressive macular hypomelanosis. Sci. Rep. 6:31968. doi: $10.1038 /$ srep31968

Bibi, F., Yasir, M., Sohrab, S. S., Azhar, E. I., Al-Qahtani, M. H., Abuzenadah, A. M., et al. (2014). Link between chronic bacterial inflammation and Alzheimer disease. CNS Neurol. Disord. Drug Targets. 13, 1140-1147. doi: $10.2174 / 1871527313666140917115741$

Bojar, R. A., and Holland, K. T. (2004). Acne and Propionibacterium acnes. Clin. Dermatol. 22, 375-379. doi: 10.1016/j.clindermatol.2004.03.005

Bollen, W. S., Gunn, B. M., Mo, H., Lay, M. K., and Curtiss, R. III. (2008). Presence of wild-type and attenuated Salmonella enterica strains in brain tissues following inoculation of mice by different routes. Infect. Immun. 76, 3268-3272. doi: 10.1128/IAI.00244-08

Braak, H., Ghebremedhin, E., Rüb, U., Bratzke, H., and Del Tredici, K. (2004). Stages in the development of Parkinson's disease-related pathology. Cell Tissue Res. 318, 121-134. doi: 10.1007/s00441-004-0956-9

Burokas, A., Moloney, R. D., Dinan, T. G., and Cryan, J. F. (2015). Microbiota regulation of the Mammalian gut-brain axis. Adv. Appl. Microbiol. 91, 1-62. doi: 10.1016/bs.aambs.2015.02.001

Chamaillard, M., Girardin, S. E., Viala, J., and Philpott, D. J. (2003). Nods, Nalps and Naip: intracellular regulators of bacterial-induced inflammation. Cell. Microbiol. 5, 581-592. doi: 10.1046/j.1462-5822.2003.00304.x

Chao, Y., Wong, S. C., and Tan, E. K. (2014). Evidence of inflammatory system involvement in Parkinson's disease. Biomed. Res. Int. 2014:308654. doi: 10.1155/2014/308654

Cogen, A. L., Nizet, V., and Gallo, R. L. (2008). Skin microbiota: a source of disease or defence? Br. J. Dermatol. 158, 442-455. doi: 10.1111/j.1365-2133.2008.08437.x

Cohen, R. J., Shannon, B. A., McNeal, J. E., Shannon, T., and Garrett, K. L. (2005). Propionibacterium acnes associated with inflammation in radical prostatectomy specimens: a possible link to cancer evolution? J. Urol. 173, 1969-1974. doi: 10.1097/01.ju.0000158161.15277.78

Collins, S. M., Surette, M., and Bercik, P. (2012). The interplay between the intestinal microbiota and the brain. Nat. Rev. Microbiol. 10, 735-742. doi: $10.1038 /$ nrmicro2876

Davidsson, S., Mölling, P., Rider, J. R., Unemo, M., Karlsson, M. G., Carlsson, J., et al. (2016). Frequency and typing of Propionibacterium acnes in prostate tissue obtained from men with and without prostate cancer. Infect. Agent Cancer 11:26. Erratum in: Infect. Agent Cancer. (2016) 11:36. doi: 10.1186/s13027-016-0074-9

de Brouwer, B., Veltkamp, M., Wauters, C. A., Grutters, J. C., and Janssen, R. (2015). Propionibacterium acnes isolated from lymph nodes of patients with sarcoidosis. Sarcoidosis Vasc Diffuse Lung Dis. 32, 271-274.

De Chiara, G., Marcocci, M. E., Sgarbanti, R., Civitelli, L., Ripoli, C., Piacentini, R., et al. (2012). Infectious agents and neurodegeneration. Mol. Neurobiol. 46, 614-638. doi: 10.1007/s12035-012-8320-7

De Marzo, A. M., Marchi, V. L., Epstein, J. I., and Nelson, W. G. (1999). Proliferative inflammatory atrophy of the prostate: implications for prostatic carcinogenesis. Am. J. Pathol. 155, 1985-1992.
Dinan, T. G., Stanton, C., and Cryan, J. F. (2013). Psychobiotics: a novel class of psychotropic. Biol. Psychiatry 74, 720-726. doi: 10.1016/j.biopsych.2013. 05.001

Dobbs, S. M., Dobbs, R. J., Weller, C., Charlett, A., Augustin, A., Taylor, D., et al. (2016). Peripheral aetiopathogenic drivers and mediators of Parkinson's disease and co-morbidities: role of gastrointestinal microbiota. J. Neurovirol. 22, 22-32. doi: $10.1007 / \mathrm{s} 13365-015-0357-8$

Drott, J. B., Alexeyev, O., Bergström, P., Elgh, F., and Olsson, J. (2010). Propionibacterium acnes infection induces upregulation of inflammatory genes and cytokine secretion in prostate epithelial cells. BMC Microbiol. 10:126. doi: 10.1186/1471-2180-10-126

Dudli, S., Liebenberg, E., Magnitsky, S., Miller, S., Demir-Deviren, S., and Lotz, J. C. (2016). Propionibacterium acnes infected intervertebral discs cause vertebral bone marrow lesions consistent with Modic changes. J. Orthop. Res. 34, 1447-1455. doi: 10.1002/jor.23265

Eishi, Y. (2013). Etiologic link between sarcoidosis and Propionibacterium acnes. Respir. Investig. 51, 56-68. doi: 10.1016/j.resinv.2013.01.001

Eishi, Y., Suga, M., Ishige, I., Kobayashi, D., Yamada, T., Takemura, T., et al. (2002). Quantitative analysis of mycobacterial and propionibacterial DNA in lymph nodes of Japanese and European patients with sarcoidosis. J. Clin. Microbiol. 40, 198-204. doi: 10.1128/JCM.40.1.198-204.2002

Fassi-Fehri, L., Mak, T. N., Laube, B., Brinkmann, V., Ogilvie, L. A., Mollenkopf, H., et al. (2011). Prevalence of Propionibacterium acnes in diseased prostates and its inflammatory and transforming activity on prostate epithelial cells. Int. J. Med. Microbiol. 301, 69-78. doi: 10.1016/j.ijmm.2010.08.014

Findley, K., and Grice, E. A. (2014). The skin microbiome: a focus on pathogens and their association with skin disease. PLoS Pathog. 10:e1004436. doi: 10.1371/journal.ppat.1004436

Funke, G., Renaud, F. N., Freney, J., and Riegel, P. (1997). Multicenter evaluation of the updated and extended API (RAPID) Coryne database 2.0. J. Clin. Microbiol. $35,3122-3126$.

Gambara, G., De Cesaris, P., De Nunzio, C., Ziparo, E., Tubaro, A., Filippini, A., et al. (2013). Toll-like receptors in prostate infection and cancer between bench and bedside. J. Cell. Mol. Med. 17, 713-722. doi: 10.1111/jcmm.12055

Graham, G. M., Farrar, M. D., Cruse-Sawyer, J. E., Holland, K. T., and Ingham, E. (2004). Proinflammatory cytokine production by human keratinocytes stimulated with Propionibacterium acnes and P. acnes GroEL. Br. J. Dermatol. 150, 421-428. doi: 10.1046/j.1365-2133.2004.05762.x

Grice, E. A., Kong, H. H., Conlan, S., Deming, C. B., Davis, J., Young, A. C., et al. (2009). Topographical and temporal diversity of the human skin microbiome. Science 324, 1190-1192. doi: 10.1126/science. 1171700

Grice, E. A., and Segre, J. A. (2011). The skin microbiome. Nat. Rev. Microbiol. 9, 244-253. Erratum in: Nat. Rev. Microbiol. (2011) 9:626. doi: 10.1038/nrmicro2537

Harris, A. E., Hennicke, C., Byers, K., and Welch, W. C. (2005). Postoperative discitis due to Propionibacterium acnes: a case report and review of the literature. Surg Neurol. 63, 538-541; discussion: 541. doi: 10.1016/j.surneu.2004.06.012

Harris, M. A., Shen, H., Marion, S. A., Tsui, J. K., and Teschke, K. (2013). Head injuries and Parkinson's disease in a case-control study. Occup. Environ. Med. 70, 839-844. doi: 10.1136/oemed-2013-101444

Hitscherich, K., Smith, K., Cuoco, J. A., Ruvolo, K. E., Mancini, J. D., Leheste, J. R., et al. (2016). The glymphatic-lymphatic continuum: opportunities for osteopathic manipulative medicine. J. Am. Osteopath. Assoc. 116, 170-177. doi: $10.7556 /$ jaoa.2016.033

Hochreiter, W. W., Nadler, R. B., Koch, A. E., Campbell, P. L., Ludwig, M., Weidner, W., et al. (2000). Evaluation of the cytokines interleukin 8 and epithelial neutrophil activating peptide 78 as indicators of inflammation in prostatic secretions. Urology 56, 1025-1029. doi: 10.1016/S0090-4295(00)00844-X

Holmqvist, S., Chutna, O., Bousset, L., Aldrin-Kirk, P., Li, W., Björklund, T., et al. (2014). Direct evidence of Parkinson pathology spread from the gastrointestinal tract to the brain in rats. Acta Neuropathol. 128, 805-820. doi: 10.1007/s00401-014-1343-6

Iliff, J. J., Wang, M., Liao, Y., Plogg, B. A., Peng, W., Gundersen, G. A., et al. (2012). A paravascular pathway facilitates CSF flow through the brain parenchyma and the clearance of interstitial solutes, including amyloid $\beta$. Sci. Transl. Med. 4, 147ra111. doi: 10.1126/scitranslmed.3003748 
Inohara, N., and Nuñez, G. (2001). The NOD: a signaling module that regulates apoptosis and host defense against pathogens. Oncogene 20, 6473-6481. doi: $10.1038 /$ sj.onc. 1204787

Jafari, S., Etminan, M., Aminzadeh, F., and Samii, A. (2013). Head injury and risk of Parkinson disease: a systematic review and meta-analysis. Mov. Disord. 28, 1222-1229. doi: $10.1002 / \mathrm{mds} .25458$

Jorgensen, I., and Seed, P. C. (2012). How to make it in the urinary tract: a tutorial by Escherichia coli. PLoS Pathog.8:e1002907. doi: 10.1371/journal.ppat.1002907

Keshavarzian, A., Green, S. J., Engen, P. A., Voigt, R. M., Naqib, A., Forsyth, C. B., et al. (2015). Colonic bacterial composition in Parkinson's disease. Mov. Disord. 30, 1351-1360. doi: 10.1002/mds.26307

Kim, J., Ochoa, M. T., Krutzik, S. R., Takeuchi, O., Uematsu, S., Legaspi, A. J., et al. (2002). Activation of toll-like receptor 2 in acne triggers inflammatory cytokine responses. J. Immunol. 169, 1535-1541. doi: 10.4049/jimmunol.169. 3.1535

Kurokawa, I., Danby, F. W., Ju, Q., Wang, X., Xiang, L. F., Xia, L., et al. (2009). New developments in our understanding of acne pathogenesis and treatment. Exp. Dermatol. 18, 821-832. doi: 10.1111/j.1600-0625.2009. 00890.x

Lee, S. E., Kim, J. M., Jeong, S. K., Jeon, J. E., Yoon, H. J., Jeong, M. K., et al. (2010). Protease-activated receptor-2 mediates the expression of inflammatory cytokines, antimicrobial peptides, and matrix metalloproteinases in keratinocytes in response to Propionibacterium acnes. Arch Dermatol. Res. 302, 745-756. doi: 10.1007/s00403-010-1074-z

Li, W., Lee, M. H., Henderson, L., Tyagi, R., Bachani, M., Steiner, J., et al. (2015). Human endogenous retrovirus-K contributes to motor neuron disease. Sci. Transl. Med. 7, 307ra153. doi: 10.1126/scitranslmed.aac8201

Mak, T. N., Fischer, N., Laube, B., Brinkmann, V., Metruccio, M. M., Sfanos, K. S., et al. (2012). Propionibacterium acnes host cell tropism contributes to vimentin-mediated invasion and induction of inflammation. Cell. Microbiol. 14, 1720-1733. doi: 10.1111/j.1462-5822.2012.01833.x

Mak, T. N., Yu, S. H., De Marzo, A. M., Brüggemann, H., and Sfanos, K. S. (2013). Multilocus sequence typing (MLST) analysis of Propionibacterium acnes isolates from radical prostatectomy specimens. Prostate 73, 770-777. doi: $10.1002 /$ pros. 22621

Mayer, E. A., Knight, R., Mazmanian, S. K., Cryan, J. F., and Tillisch, K. (2014). Gut microbes and the brain: paradigm shift in neuroscience. J. Neurosci. 34, 15490-15496. doi: 10.1523/JNEUROSCI.3299-14.2014

Mechergui, Y. B., Ben Jemaa, A., Mezigh, C., Fraile, B., Ben Rais, N., Paniagua, R., et al. (2009). The profile of prostate epithelial cytokines and its impact on sera prostate specific antigen levels. Inflammation 32, 202-210. doi: 10.1007/s10753-009-9121-7

Menschikowski, M., Hagelgans, A., Fuessel, S., Mareninova, O. A., Asatryan, L., Wirth, M. P., et al. (2013). Serum amyloid A, phospholipase $A_{2}$-IIA and Creactive protein as inflammatory biomarkers for prostate diseases. Inflamm. Res. 62, 1063-1072. doi: 10.1007/s00011-013-0665-5

Moreira, L. O., and Zamboni, D. (2012). S. NOD1 and NOD2 Signaling in infection and inflammation. Front. Immunol. 3:328. doi: 10.3389/fimmu.2012.00328

Nagy, I., Pivarcsi, A., Kis, K., Koreck, A., Bodai, L., McDowell, A., et al. (2006). Propionibacterium acnes and lipopolysaccharide induce the expression of antimicrobial peptides and proinflammatory cytokines/chemokines in human sebocytes. Microbes Infect. 8, 2195-2205. doi: 10.1016/j.micinf.2006. 04.001

Nelson, W. G., De Marzo, A. M., DeWeese, T. L., and Isaacs, W. B. (2004). The role of inflammation in the pathogenesis of prostate cancer. J. Urol. $172(5 \mathrm{Pt}$ 2):S6-S11; discussion: S11-S2. doi: 10.1097/01.ju.0000142058.99614.ff

Ni, X., Meng, H., Zhou, F., Yu, H., Xiang, J., and Shen, S. (2016). Effect of hypertension on bacteria composition of prostate biopsy in patients with benign prostatic hyperplasia and prostate cancer in PSA grey-zone. Biomed. Rep. 4, 765-769. doi: 10.3892/br.2016.655

Oh, J., Byrd, A. L., Deming, C., Conlan, S., NISC Comparative Sequencing, Program, Kong, H. H., et al. (2014). Biogeography and individuality shape function in the human skin metagenome. Nature 514, 59-64. doi: 10.1038/nature13786

Olsson, J., Drott, J. B., Laurantzon, L., Laurantzon, O., Bergh, A., and Elgh, F. (2012). Chronic prostatic infection and inflammation by Propionibacterium acnes in a rat prostate infection model. PLOS ONE 7:e51434. doi: 10.1371/journal.pone.0051434. Erratum in: PLoS ONE (2013) 8. doi: 10.1371/annotation/2160e616-aa79-4097-96ab-e143d2a4d136

Pearce, N., Gallo, V., and McElvenny, D. (2015). Head trauma in sport and neurodegenerative disease: an issue whose time has come? Neurobiol. Aging 36, 1383-1389. doi: 10.1016/j.neurobiolaging.2014.12.024

Perry, A., and Lambert, P. (2011). Propionibacterium acnes: infection beyond the skin. Expert Rev. Anti Infect. Ther. 9, 1149-1156. doi: 10.1586/eri.11.137

Portillo, M. E., Corvec, S., Borens, O., and Trampuz, A. (2013). Propionibacterium acnes: an underestimated pathogen in implant-associated infections. Biomed. Res Int. 2013:804391. doi: 10.1155/2013/804391

Potgieter, M., Bester, J., Kell, D. B., and Pretorius, E. (2015). The dormant blood microbiome in chronic, inflammatory diseases. FEMS Microbiol. Rev. 39, 567-591. doi: 10.1093/femsre/fuv013

Rajasekaran, S., Tangavel, C., Aiyer, S. N., Nayagam, S. M., Raveendran, M., Demonte, N. L., et al. (2017). Is infection the possible initiator of disc disease? An insight from proteomic analysis. Eur. Spine J. doi: 10.1007/s00586-017-4972-3. [Epub ahead of print].

Sanford, J. A., Zhang, L., Williams, M. R., Gangoiti, J. A., Huang, C., and Gallo, R. L. (2016). Inhibition of HDAC8 and HDAC9 by microbial short-chain fatty acids breaks immune tolerance of the epidermis to TLR ligands. Sci. Immunol. 1. doi: 10.1126/sciimmunol.aah4609

Scharschmidt, T. C., Vasquez, K. S., Truong, H. A., Gearty, S. V., Pauli, M. L., Nosbaum, A., et al. (2015). A wave of regulatory $t$ cells into neonatal skin mediates tolerance to commensal microbes. Immunity 43, 1011-1021. doi: 10.1016/j.immuni.2015.10.016

Scheperjans, F., Aho, V., Pereira, P. A., Koskinen, K., Paulin, L., Pekkonen, E., et al. (2015). Gut microbiota are related to Parkinson's disease and clinical phenotype. Mov. Disord. 30, 350-358. doi: 10.1002/mds.26069

Schupp, J. C., Tchaptchet, S., Lützen, N., Engelhard, P., Müller-Quernheim, J., Freudenberg, M. A., et al. (2015). Immune response to Propionibacterium acnes in patients with sarcoidosis-in vivo and in vitro. BMC Pulm Med. 15:75. doi: 10.1186/s12890-015-0070-7

Sfanos, K. S., Hempel, H. A., and De Marzo, A. M. (2014). The role of inflammation in prostate cancer. Adv. Exp. Med. Biol. 816, 153-181. doi: 10.1007/978-3-0348-0837-8_7

Sfanos, K. S., Isaacs, W. B., and De Marzo, A. M. (2013). Infections and inflammation in prostate cancer. Am. J. Clin. Exp. Urol. 1, 3-11.

Sfanos, K. S., Sauvageot, J., Fedor, H. L., Dick, J. D., De Marzo, A. M., and Isaacs, W. B. (2008). A molecular analysis of prokaryotic and viral DNA sequences in prostate tissue from patients with prostate cancer indicates the presence of multiple and diverse microorganisms. Prostate 68, 306-320. doi: 10.1002/pros.20680

Shinohara, D. B., Vaghasia, A. M., Yu, S. H., Mak, T. N., Brüggemann, H., Nelson, W. G., et al. (2013). A mouse model of chronic prostatic inflammation using a human prostate cancer-derived isolate of Propionibacterium acnes. Prostate 73, 1007-1015. doi: 10.1002/pros.22648

Spadoni, I., Zagato, E., Bertocchi, A., Paolinelli, R., Hot, E., Di Sabatino, A., et al. (2015). A gut-vascular barrier controls the systemic dissemination of bacteria. Science 350, 830-834. doi: 10.1126/science.aad0135

Svensson, E., Horváth-Puh,ó, E., Thomsen, R. W., Djurhuus, J. C., Pedersen, L., Borghammer, P., et al. (2015). Vagotomy and subsequent risk of Parkinson's disease. Ann. Neurol. 78, 522-529. doi: 10.1002/ana.24448

Tanabe, T., Ishige, I., Suzuki, Y., Aita, Y., Furukawa, A., Ishige, Y., et al. (2006). Sarcoidosis and NOD1 variation with impaired recognition of intracellular Propionibacterium acnes. Biochim. Biophys. Acta 1762, 794-801. doi: 10.1016/j.bbadis.2006.07.006

Taylor, J. P., Hardy, J., and Fischbeck, K. H. (2002). Toxic proteins in neurodegenerative disease. Science 296, 1991-1995. doi: 10.1126/science.1067122

Tsai, H. H., Lee, W. R., Wang, P. H., Cheng, K. T., Chen, Y. C., and Shen, S. C. (2013). Propionibacterium acnes-induced iNOS and COX-2 protein expression via ROS-dependent NF- $\mathrm{B}$ and AP-1 activation in macrophages. J. Dermatol. Sci. 69, 122-131. doi: 10.1016/j.jdermsci.2012.10.009

Uçkay, I., Dinh, A., Vauthey, L., Asseray, N., Passuti, N., Rottman, M., et al. (2010). Spondylodiscitis due to Propionibacterium acnes: report of twentynine cases and a review of the literature. Clin. Microbiol. Infect. 16, 353-358. doi: 10.1111/j.1469-0691.2009.02801.x 
Urquhart, D. M., Zheng, Y., Cheng, A. C., Rosenfeld, J. V., Chan, P., Liew, S., et al. (2015). Could low grade bacterial infection contribute to low back pain? A systematic review. BMC Med. 13:13. doi: 10.1186/s12916-015-0267-x

Vizcarra, J. A., Wilson-Perez, H. E., and Espay, A. J. (2015). The power in numbers: gut microbiota in Parkinson's disease. Mov. Disord. 30, 296-298. doi: $10.1002 / \mathrm{mds} .26116$

Wang, B., Yang, W., Wen, W., Sun, J., Su, B., Liu, B., et al. (2010). Gamma-secretase gene mutations in familial acne inversa. Science 330, 1065. doi: 10.1126/science.1196284

Werner, J. L., Escolero, S. G., Hewlett, J. T., Mak, T. N., Williams, B. P., Eishi, Y., et al. (2017). Induction of pulmonary granuloma formation by Propionibacterium acnes is regulated by MyD88 and Nox2. Am. J. Respir Cell. Mol. Biol. 56, 121-130. doi: 10.1165/rcmb.2016-0035OC

Yamada, T., Eishi, Y., Ikeda, S., Ishige, I., Suzuki, T., Takemura, T., et al. (2002). In situ localization of Propionibacterium acnes DNA in lymph nodes from sarcoidosis patients by signal amplification with catalysed reporter deposition. J. Pathol. 198, 541-547. doi: 10.1002/path.1243

Yu, H., Meng, H., Zhou, F., Ni, X., Shen, S., and Das, U. N. (2015). Urinary microbiota in patients with prostate cancer and benign prostatic hyperplasia. Arch. Med. Sci. 11, 385-394. doi: 10.5114/aoms.2015.50970

Yu, Y., Champer, J., Agak, G. W., Kao, S., Modlin, R. L., and Kim, J. (2016). Different Propionibacterium acnes phylotypes induce distinct immune responses and express unique surface and secreted proteomes. J. Invest. Dermatol. 136, 2221-2228. doi: 10.1016/j.jid.2016.06.615

Zhou, Z., Chen, Z., Zheng, Y., Cao, P., Liang, Y., Zhang, X., et al. (2015). Relationship between annular tear and presence of Propionibacterium acnes in lumbar intervertebral disc. Eur. Spine J. 24, 2496-2502. doi: 10.1007/s00586-015-4180-y

Zwijnenburg, P. J., van der Poll, T., Florquin, S., van Deventer, S. J., Roord, J. J., and van Furth, A. M. (2001). Experimental pneumococcal meningitis in mice: a model of intranasal infection. J. Infect Dis. 183, 1143-1146. doi: 10.1086/ 319271

Conflict of Interest Statement: The authors declare that the research was conducted in the absence of any commercial or financial relationships that could be construed as a potential conflict of interest.

Copyright (c) 2017 Leheste, Ruvolo, Chrostowski, Rivera, Husko, Miceli, Selig, Brüggemann and Torres. This is an open-access article distributed under the terms of the Creative Commons Attribution License (CC BY). The use, distribution or reproduction in other forums is permitted, provided the original author (s) or licensor are credited and that the original publication in this journal is cited, in accordance with accepted academic practice. No use, distribution or reproduction is permitted which does not comply with these terms. 